\title{
The Relationship Between Cognitive Adaptability and Entrepreneurial Decision-making Quality: A Moderating Effect of Environmental Uncertainty
}

\author{
Rui Xing ${ }^{1}$, Nan Zhou ${ }^{1}$, Zhanpeng Dang ${ }^{2}$ and Guohong Wang ${ }^{1, *}$ \\ ${ }^{1}$ DUT School of Economics and Management, Dalian University of Technology, Dalian, Liaoning116024, China \\ ${ }^{2}$ Chengdu Chaoyouai Technology Co., LTD, Chengdu, Sichuan 610096, China \\ *Corresponding author. Email: wanggh@dlut.edu.cn
}

\begin{abstract}
This research examined the relationship between five dimensions of cognitive adaptability and the decisionmaking quality, and explored the role of environmental uncertainty as a moderator. Implemented with Chinese entrepreneurs as research objectives, the empirical study shows that the effects of five dimensions of cognitive adaptability on decision-making quality are different. Expressly, the significant positive impact of cognitive adaptability on entrepreneurial decision-making quality indicates two dimensions: entrepreneurs' goal orientation and monitoring. It also found environment uncertainty has diversified moderating effects on the relationship between cognitive adaptability and decision-making quality. As one of the first attempts at introducing the person-environment fit theory into entrepreneurial cognition researches, the paper gives insight into the relationship between cognitive adaptability and decision-making quality under dynamic environmental context.
\end{abstract}

Keywords: cognitive adaptability, decision-making quality, environmental uncertainty, metacognition

\section{INTRODUCTION}

To maintain and establish their competitive advantages in the highly uncertain entrepreneurial context, entrepreneurs need rapidly judge whether to develop a market opportunity or not, react instantly to risks and crises, and make the corresponding adjustment to environmental changes. All of these activities are closely associated with entrepreneurs' cognitive capability and decision-making. However, the issue of high-quality entrepreneurial decision-making mechanisms in an uncertain context is still less discussed.

Prior research in strategic decision-making indicates that organizations' performance largely relies on managers' decision-making quality and strategy implementation [1]. Entrepreneurs' decision-making context is always full of uncertainty. Specifically, R\&D of new products, the entry into new markets, and the application of new techniques are all experiments based on unknown results. During this situation, whether entrepreneurs can correctly make decision in an uncertain context determines the new ventures' capability on 'how far it can go' and 'how big it can grow.

Studies on strategic decision-making regard entrepreneurial decision-makers as groups of people with unique thoughts and behavioral modes characteristics [2]. Some of these studies proved that entrepreneurs' heuristicdriven bias negatively influences entrepreneurial decisionmaking [3]. Since most existing studies conducted large established enterprises and TMT as research objects, the interaction between entrepreneurs' cognition and decisionmaking contexts and its complicated effect on entrepreneurial decision-making is unclear. Thus, whether the conclusion is effective to start-ups and entrepreneurial teams or not needs further examination.

According to the cognitive perspective in entrepreneurship, entrepreneurs' cognition leads to understanding the external context, recognizing opportunities, and judgment on the strategic management of new firms, thus playing an essential role in decision-making quality. Cognitive adaptability refers to how entrepreneurs give feedback by embedding cognitive processes into the environment and adjusting their decision-making approach effectively and adequately, which emphasizes the effect of entrepreneurs' self-reflection and self-adjustment on cognitive process and ability [4].

Above on, our research conducted empirical studies on the relationship between entrepreneurs' cognitive adaptability and the quality of decision-making under the background of environmental uncertainty. The aim of our research is to explore whether and under what conditions entrepreneurs' cognitive adaptability can be more beneficial in generating high-quality entrepreneurial decision-making. 


\section{THE THEORY BACKGROUND AND HYPOTHESES}

\subsection{Cognitive Adaptability}

Cognitive actions occur in the dynamic interaction among the body of the subjective, the circumstances, and the social environment. Ireland et al. stated that successful strategists in the future would apply a kind of entrepreneurial thought, flexible and adaptive thinking with the ability that can immediately perceive, take actions and mobilize in uncertain conditions [5]. Haynie and Shepherd considered entrepreneurial thought as part of situational awareness studies and propose the concept of cognitive adaptability based on a metacognitive perspective. Cognitive adaptability emphasizes individuals' ability to proactively cope with environmental changes to reach their aims. Entrepreneurs with high levels of cognitive adaptability generally make the proper adjustments on the entrepreneurial tasks and then develop environmental changes into new opportunities [6].

\subsection{Environmental Uncertainty}

Environmental factors are some of the critical external factors faced in the process of entrepreneurial decisionmaking. Entrepreneurs' perceptions and predictions regarding the external environment play critical roles in pursuing opportunities and developing valuable strategies. Environmental uncertainty is one of the most significant contextual features. In an uncertain environment, the traditional managerial decision-making mode based on prediction is unlikely to work. Entrepreneurs need to adjust decisions according to environmental changes constantly. Both theories and practices show that dynamics and hostility are two significant characteristics of environmental uncertainty. Specifically, dynamics is reflected in changing frequency and the degree of instability of technology, customer demand, and raw material supply [7]. Hostile is characterized by precarious industry settings, intense competition, harsh, overwhelming business climates, and the relative lack of exploitable opportunities. Thus, we conducted environmental uncertainty as a combination of environmental dynamics and hostility.

\subsection{Entrepreneurial Decision-making Quality}

Decision-making quality refers to the decisive effect and the contingency ability to solve problems in the decision execution process and to adjust strategies following the actual situation [8]. In this study, we regarded all entrepreneurial activities as entrepreneurial decisionmaking occasions, which adopted a comparatively broad definition of entrepreneurial decision-making. In both establishing and growing enterprises, many issues like opportunity recognition and evaluation, and the entrepreneurial entry and quit would influence their success. Therefore, we defined entrepreneurial decisionmaking quality in this paper as follow: the ability of decision-making speed and effect in the process of opportunity identification, evaluation, and development as reflected by decision-making, as well as the contingency ability to solve problems during decision execution and to adjust goals and strategies following environmental changes in an uncertain environment.

\subsection{Entrepreneurs' Cognitive Adaptability and Entrepreneurial Decision-making Quality}

Evidence from prior studies has suggested that entrepreneurs' cognitive adaptability directly affects risk decision-making effect. The formation process of decision-making is relative to the existing cognitive structure: entrepreneurs constantly search for and obtain information from an uncertain environment, process the information and then make decisions. In an uncertain environment, cognitive ability manifests itself more as entrepreneurs' cognitive adaptability. According to Person-Environment Fit Theory, entrepreneurs' cognitive adaptability is a dynamic ability, showing the process that entrepreneurs constantly enhance their cognitive ability through the interaction with the environment. Hence, the stronger entrepreneurs' cognitive adaptability is, the more likely they will optimize their entrepreneurial decisions and behaviors through cognitive feedback. Cognitive adaptability includes five dimensions: goal orientation, metacognitive knowledge, metacognitive experience, metacognitive choice, and monitoring.

Among them, goal orientation refers to the extent to which the individual interprets environmental variations in light of a wide variety of personal, social, and organizational goals. Goal orientation serves to engage the feedback information in an entrepreneurial environment timely. Due to goal orientation, entrepreneurs could optimize their decision-making modes, revise the future developing direction, and reinforce their environmental adaptability.

Therefore, we pointed out that the stronger entrepreneurs' goal orientation is, the more likely they can accurately judge the rationality of current goals, show more substantial commitment and determination towards the goals, and enhance decision-making efficiency.

Metacognitive knowledge refers to the extent to which the individual relies on what is already known about themselves, other people, tasks, and strategies when generating multiple decision frameworks focusing on interpreting, planning, and implementing goals to 'manage' a changing environment. Conscious thinking includes understanding individuals' preferences, the personal style to deal with the environment, and the advantages and disadvantages of tasks. Metacognitive knowledge in an entrepreneurial context shows entrepreneurs' cognitive ability on themselves, others, tasks, strategies, and interaction when setting a few decision-making strategies 
for regulation and realizing entrepreneurial goals [9]. Furthermore, prior researches have shown that the ability strengthens entrepreneurs' ability to learn from environmental changes and virtually adapt to environmental uncertainty effectively [10]. Therefore, the paper suggested that metacognitive knowledge is positive to the improvement of decision-making quality. Metacognitive experience refers to the extent to which the individual relies on idiosyncratic experiences, emotions, and intuitions when engaging in the process of generating multiple decision frameworks focused on interpreting, planning, and implementing goals to 'manage' a changing environment. Cognitive subjects' variant emotional reaction generates in the monitoring of current cognitive actions [11].

In an entrepreneurial context, metacognitive experience shows the cognitive ability of unique experience, emotion, and intuition when entrepreneurs set a few powerful strategies for programs and entrepreneurial goal realization. Concretely, metacognitive experience manifests as two statuses, negative and positive [12]. When the entrepreneurial tasks performed by the entrepreneurs do not match the pre-established goals, or the entrepreneurial environments change, the positive metacognitive experience would mobilize the prior successful entrepreneurial experience, improve the speed and effectiveness of cognitive processing, and quickly make decisions. However, a negative metacognitive experience would cause entrepreneurs to give up the ideas and make entrepreneurs spend much time and energy rethinking and discussing the content of decision-making, which reduces the decision-making efficiency and the confidence in the realization of goals. Thus, we suggested that entrepreneurs' metacognitive experience has a negative effect on decision-making quality.

Entrepreneurs generally make several alternative strategies to complete the entrepreneurial tasks most efficiently when carrying out entrepreneurial behavior actions. In an entrepreneurial context, metacognitive choice is a process that entrepreneurs select specific strategies from many available alternative schemes in terms of goal orientation. Thus, we suggested that entrepreneurs' metacognitive choice positively affects the improvement of decision-making quality.

Monitoring is defined as the ability relative to 'managing' a changing environment. Such as seeking and using feedback to reevaluate goal orientation, metacognitive knowledge, metacognitive experience, and metacognitive choice. Monitoring the extent to which actual performance matches the goal helps individuals evaluate their selection of a particular decision framework. Through monitoring, entrepreneurs can dynamically track, evaluate and feedback on decisions and their implementation, and then timely and effectively regulate decision-making strategies to realize entrepreneurial goals. Therefore, we hypothesized that:

Hla: Entrepreneurs' goal orientation has a positive impact on entrepreneurial decision-making quality.
H1b: Entrepreneurs' metacognitive knowledge has a positive impact on entrepreneurial decision-making quality.

H1c: Entrepreneurs' metacognitive knowledge has a negative impact on decision-making quality.

H1d: Entrepreneurs' metacognitive choice has a positive impact on entrepreneurial decision-making quality.

Hle: Entrepreneurs' monitoring has a positive impact on entrepreneurial decision-making quality.

\subsection{Moderating Effect of Environmental Uncertainty}

Cognitive adaptability describes a concept associated with entrepreneurs' uncertain task context. And the effect of entrepreneurs' cognitive adaptability in different degrees of environmental uncertainty is different. It was indicated from Carpenter and Fredrickson's empirical studies that the degree of environmental uncertainty would influence senior executives' choices in enterprises [13]. When the degree of environmental uncertainty is lower, external environmental factors like technological innovation and competitive threats are in comparatively steady and easily predictable states. At this time, with the appropriate use of decision-making methods, entrepreneurs can predict market demand more accurately and then make correct decisions. However, in a highly uncertain environment, the potential market demand is almost impossible to predict all sorts of threats: goals are usually vague, thus entrepreneurs' ability to accurately predict information is weakened. Entrepreneurs need to integrate their knowledge structure through cognitive adaptability. They also have to adjust goals timely according to the external environment, internal resources and abilities, and to make decisions matched with environmental changes. Therefore, we considered that environmental uncertainty is an important moderator for entrepreneurs' cognitive adaptability to influence decision-making quality.

Specifically, high environmental uncertainty amplifies the direct effect of CEO learning goal orientation on TMT learning goal orientation [14], which potentially enhances the start-ups' internal decision-making abilities in coping with risks and challenges. Similarly, in a highly uncertain environment, entrepreneurs would rapidly collect and process relative information to lower the time cost on obtaining relative information, help entrepreneurs evaluate the strategies accurately and enhance decision-making speed and efficiency [15]. Besides, Haynie and Shepherd supposed that metacognitive experience generally appears when entrepreneurs feel it impossible to finish a specific ongoing entrepreneurial task [6]. The uncertainty in the entrepreneurial environment increases the difficulty of entrepreneurial success and the risk of entrepreneurial failure. Therefore, the higher the degree of environmental uncertainty is, the more likely it is to stimulate the entrepreneurs' own metacognitive experience, and the stronger the impact of metacognitive experience on decision-making quality is. 
Meanwhile, the more uncertain the entrepreneurial environment is, the more difficult it is to predict the market demands and competitors' behavior, which enhances entrepreneurs' difficulties in alternative strategies evaluation and selection. In the meanwhile, an entrepreneur's metacognitive choice ability has a more significant impact on decision quality. Finally, monitoring can help entrepreneurs quickly recognize and absorb the feedback information in the entrepreneurial process, especially the negative feedback information.

When the degree of environmental uncertainty is higher, the more negative feedback information would be, just like changes in customers' demand. Entrepreneurs who have a higher degree of recognition and commitment to entrepreneurial goals would be strongly willing and motivated to analyze the feedback information. They also would adopt some amendments and adjustments to ensure the decision-making quality and solve problems in the entrepreneurial process. Therefore, we hypothesized that:

H2: Environmental uncertainty significantly moderates the relationship between cognitive adaptability and decision-making quality.

H2a: Environmental uncertainty positively moderates the relationship between entrepreneurs' goal orientation and decision-making quality.

$H 2 b$ : Environmental uncertainty positively moderates the relationship between entrepreneurs' metacognitive knowledge and decision-making quality.

H2c: Environmental uncertainty positively moderates the relationship between entrepreneurs' metacognitive experience and decision-making quality.

H2d: Environmental uncertainty positively moderates the relationship between entrepreneurs' metacognitive choice and decision-making quality.

H2e: Environmental uncertainty positively moderates the relationship between entrepreneurs' monitoring and decision-making quality.

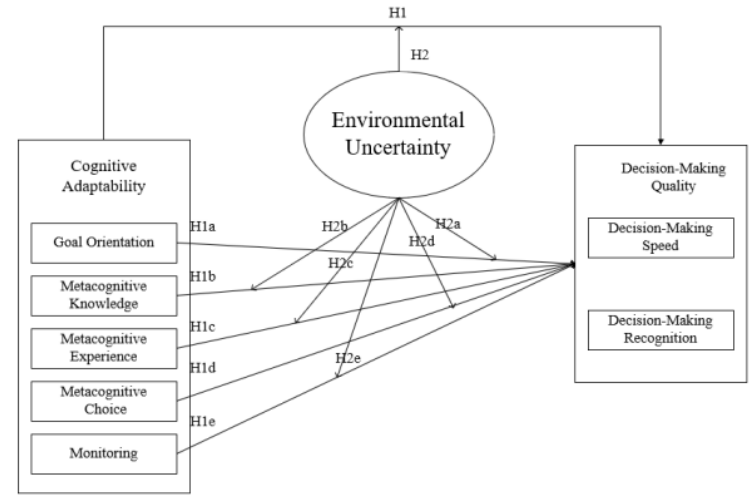

Figure 1. Research Framework

\section{METHODOLOGY}

\subsection{Sample and Data Collection}

We collected data from company founders, team leaders, and company executives involved in entrepreneurial decision-making. Data were collected via web-based surveys and face-to-face interviews at two points over seven months. The final 183 valid samples were with a response rate of $76 \%$. Sample enterprises were located in 21 provinces, including Shandong, Liaoning, Gansu, etc. The industries included transportation, information software, finance, catering, real estate, and commerce, among which the information software industry accounted for $25.1 \%$, with the largest proportion. Respondents age below 25 accounted for $15 \%$, between 26 and 45 accounted for $79 \%$, and above 46 accounted for $6 \%$. Among them, $37.7 \%$ were female, and $85.3 \%$ had a college degree.

\subsection{Measures}

Entrepreneurs' cognitive adaptability. After modifying the scale developed by Haynie and Shepherd based on respondents' feedback, our formal scale includes 20 items. Entrepreneurial decision-making quality. The scale consists of two dimensions of decision-making speed and recognition includes six items in total [16].

Environmental uncertainty. Most of the items are from the scale developed by Miller and Frieson [17]. The study measures environmental uncertainty from dynamics and hostility containing six items.

Controlled variable. We choosed two types of controlled variables: variables related to enterprises, including the enterprises' dates of establishment and the industries they are in; the other is variables related to entrepreneurs, including age, gender, and educational background.

\section{RESULTS}

\subsection{Reliability and Validity Analysis}

Before testing our hypotheses, we conducted a reliability and validity analysis. The consistency coefficients of each internal variable all exceed or approach 0.7 , indicating that the questionnaire has good reliability.

Table 1 shows the result of confirmatory factor analysis (CFA). It notes that each index reaches an ideal result, and the overall five factors structural model of cognitive adaptability provides a good fit. The same method is taken on the decision-making quality and environmental uncertainty to conduct CFA. In addition to RMSEA of decision-making quality which exceed 0.08 a bit, every other index reaches the ideal value indicating that the scale has good validity. 


\subsection{Hypothesis Tests Result}

We used multiple regression analysis to test the hypotheses following the moderation analysis method by Hayes et al. [18]. The interaction term is generated after mean centering is taken on the independent and moderating variables to make the regression equation coefficients more explanatory. After centering, the interaction term represents the moderation effect, that is, the additional influence on the variable when two variables coexist.

Table 1. Confirmatory Factor Analysis of Variables

\begin{tabular}{|c|c|c|c|c|c|c|}
\hline Variable & $\mathbf{X}^{\mathbf{2}} \mathbf{d f}$ & RMSEA & RMR & GFI & IFI & CFI \\
\hline Cognitive adaptability & 1.28 & 0.04 & 0.04 & 0.92 & 0.97 & 0.97 \\
\hline Decision-making quality & 3.10 & 0.11 & 0.05 & 0.96 & 0.93 & 0.92 \\
\hline Environmental uncertainty & 1.36 & 0.04 & 0.03 & 0.98 & 0.99 & 0.99 \\
\hline
\end{tabular}

As summarized in Table 2, Model 1 inspects controlled variables' impact on dependent variables. It shows that the educational level of entrepreneurs and the company's age are significantly positively correlated with decisionmaking quality. Model 2 examines the effect of the five dimensions of cognitive adaptability on decision-making quality. Two variables of goal orientation ( $\beta=0.23$, $\mathrm{p}<0.01)$ and monitoring $(\beta=0.17, \mathrm{p}<0.1)$ have a significant positive affect on decision-making quality. And metacognitive experience has a significant negative affect on decision-making quality $(\beta=-0.24, \mathrm{p}<0.01$ ), thus $\mathrm{H} 1 \mathrm{a}, \mathrm{H} 1 \mathrm{c}$, and H1e are supported. In contrast, metacognitive knowledge and metacognitive choice negatively correlated with decision- making quality, but they do not reach the significance level. Therefore, H1b and H1d are not supported. Based on the above, $\mathrm{H} 1$ is partially supported.

Model 3 and Model 4 test the effect of environmental uncertainty on the relationship between entrepreneurs' cognitive adaptability and decision-making quality. The changes in R2 and regression coefficients suggest that environmental uncertainty significantly and positively moderates the impact on goal orientation to decisionmaking quality. $(\beta=0.31, \mathrm{p}<0.05)$. While environmental uncertainty significantly negatively moderates the impact of metacognitive knowledge on the decision-making quality. Thus, $\mathrm{H} 2 \mathrm{a}$ is supported, but $\mathrm{H} 2 \mathrm{~b}, \mathrm{H} 2 \mathrm{c}, \mathrm{H} 2 \mathrm{~d}$, and $\mathrm{H} 2 \mathrm{e}$ are not supported. Based on the above, $\mathrm{H} 2$ is partially supported.

Table 2. Regression Analysis Results

\begin{tabular}{|c|c|c|c|c|}
\hline \multirow{2}{*}{ Explanatory Variable } & \multicolumn{4}{|c|}{ Predicted Variable } \\
\hline & Model 1 & Model 2 & Model 3 & Model 4 \\
\hline Sex & 0.01 & -0.01 & 0.01 & 0.050 \\
\hline Age & -0.07 & -0.07 & -0.07 & -0.09 \\
\hline Educational background & $0.10^{*}$ & $0.10^{*}$ & $0.10^{*}$ & $0.10^{*}$ \\
\hline Enterprise age & $0.07^{* *}$ & $0.06^{* *}$ & $0.07^{* *}$ & $0.06^{*}$ \\
\hline Industry & 0.01 & 0.01 & 0.02 & 0.02 \\
\hline Goal orientation & & $0.23^{* * *}$ & $0.24^{* * *}$ & $0.22^{* *}$ \\
\hline Metacognitive knowledge & & -0.01 & 0.007 & 0.07 \\
\hline Metacognitive experience & & $-0.24^{* * *}$ & $-0.23^{* * *}$ & $-0.26^{* * *}$ \\
\hline Metacognitive choice & & -0.03 & -0.03 & -0.05 \\
\hline Monitoring & & $0.17^{*}$ & 0.13 & $0.11^{* *}$ \\
\hline Environmental uncertainty & & & $0.13^{*}$ & $0.13^{*}$ \\
\hline Goal orientation $\times$ Environmental uncertainty & & & & $0.31^{* *}$ \\
\hline Metacognitive knowledge $\times$ Environmental uncertainty & & & & $-0.39^{* *}$ \\
\hline Metacognitive experience $\times$ Environmental uncertainty & & & & -0.08 \\
\hline Metacognitive choice $\times$ Environmental uncertainty & & & & 0.12 \\
\hline Monitoring $\times$ Environmental uncertainty & & & & 0.01 \\
\hline Model & 0.06 & 0.15 & 0.17 & 0.23 \\
\hline Variation & & 0.10 & 0.02 & 0.06 \\
\hline F-statistics & $2.05^{*}$ & $3.11^{* * *}$ & $3.15^{* * *}$ & $3.03^{* * *}$ \\
\hline
\end{tabular}




\section{DISCUSSION}

The study was conducted under the 'Person-Environment Fit' perspective, and discussed the impact of cognitive adaptability on entrepreneurial decision-making quality in an uncertain environment. The results show that:

(1) The impacts of the five dimensions of cognitive adaptability on decision-making quality are discrepant. Cognitive adaptability's significant positive effect on entrepreneurial decision-making quality is directly shown through two dimensions: entrepreneurs' goal orientation and monitoring; metacognitive knowledge, metacognitive choice, and metacognitive experience all negatively affect the decision-making quality, but only the impact of the metacognitive experience is significant. The reason for this result is suggested that explicit goal orientation and monitoring are more important to enhance entrepreneurs' decision-making quality compared with metacognition.

(2) The moderating effect of environmental uncertainty on the relationship between five dimensions of cognitive adaptability and decision-making quality is diversified. We found differences in how entrepreneurs' cognitive adaptability relates to decision-making quality partially depending on environmental uncertainty. Specifically, environmental uncertainty moderates significantly and positively the relationship between goal orientation and decision quality, which indicates that entrepreneurs with a higher degree of goal orientation can better effectively keep decision-making cognition in control in highly uncertain entrepreneurial environments. Meanwhile, environmental uncertainty significantly negatively moderates the relationship between metacognitive knowledge and decision-making quality. That means the stimulation effect of metacognitive knowledge on the improvement of decision-making quality would be weakened when the degree of environmental uncertainty is higher.

\subsection{Theoretical Contributions}

Our research has three theoretical implications: First, this study connected the decision-making and cognitive adaptability literature to demonstrate that the cognitive characteristics of entrepreneurs are particularly relevant to the quality of decision-making, revealing under what conditions entrepreneurs' cognitive adaptability can be more beneficial in generating high-quality entrepreneurial decision-making.

Second, prior studies on cognitive adaptability generally regard it as an integral concept. However, this paper discussed the different effects of the interaction between five dimensions of entrepreneurs' cognitive adaptability and environmental uncertainty to entrepreneurial decisionmaking. We found differences in the sensitivity of five dimensions of entrepreneurial cognitive adaptability to environmental uncertainty. Thus, our research refined the studies in cognitive adaptability and promoted its theoretical development.
Our research makes the third contribution by introducing Person-Environment Fit Theory into entrepreneurial cognition studies. It highlighted the multiple moderating roles of environmental uncertainty in the relationship between entrepreneurs' cognitive adaptability and decision-making, providing a richer understanding of the existing framework of 'contextthinking-behavior' in entrepreneurial cognition research.

\subsection{Practical Implications}

The finding of the study sheds light on wiser decisionmaking in an uncertain environment for entrepreneurs. First, the entrepreneurs are inspired to develop more robust cognitive adaptability to cope with unexpected threats and tasks in an uncertain environment. Our empirical studies indicated cognitive adaptability's significance, which broadly affects entrepreneurs' recognition, opportunity evaluation, and self-reflection of decisions. Entrepreneurs with a higher level of cognitive adaptability perform better in decisionmaking. Second, Entrepreneurs are supposed to prudently make strategic decisions in terms of metacognitive knowledge since an entire duplicate application of their prior management experience may be unfit to the current situation under an environment full of uncertainty. It is better to avoid being overconfident about past management experience, for it is not always reliable. Additionally, entrepreneurs should constantly pay attention to the external and internal changes, make proper adjustments on decisionmaking strategies following those changes, and improve their cognitive adaptability.

\subsection{Potential Limitations and Future Directions}

We must acknowledge several limitations of our studies that suggest directions for future research. First, the study discussed the relationship between five dimensions of entrepreneurial cognitive adaptability and decision-making quality separately. In contrast, their interaction and influence on decision-making quality were not fully considered. In future research, scholars should conduct more on the internal relationship between five dimensions of cognitive adaptation and their impact on entrepreneurial behaviors and performance. Second, our research conducted entrepreneurs' nature factors like gender, age, personalities as controlled variables in the regression analysis model. In entrepreneurship practice, these factors may be significantly relavant to entrepreneurs' cognition and then influence the quality of decisionmaking. Hence, future studies should take these factors as independent variables or moderators into the analysis model, which sheds light on cognitive adaptability and 
strategic decision-making studies with a more integrated framework.

\section{CONCLUSION}

The insights from our research are the byproduct of bringing together two essential impact factors of entrepreneurial decision-making, adaptability of cognition and context of cognition, to explore thoroughly how cognitive adaptability affects entrepreneurial decision-making and the moderation role of environment uncertainty during this process. Our findings indicated that five dimensions of cognitive adaptability influence decision-making quality differently due to diversified moderating effects of environmental uncertainty. In future research, scholars should refine and extend our work to shed further light on the generation mechanism of high-quality decision-making and drive academic attention to the unique context of entrepreneurial decision-making.

\section{ACKNOWLEDGMENT}

We gratefully acknowledge the assistance of The National Social Science Fund of China, which provides financial assistance to our project named "Researches on the Mechanism of New Energy Vehicle Multi-agent Innovation under Digital Economy(21BGL056).”

\section{REFERENCES}

[1]R.S. Dooley and G.E. Fryxell, “Attaining decision quality and commitment from dissent: the moderating effects of loyalty and competence in strategic decisionmaking teams", Academy of Management Journal, New York, vol.42, pp.389-402,1999. DOI:

https://doi.org/10.5465/257010

[2]L. Gudonavičius and J.O. Fayomi, “The relation between entrepreneurial personality and strategic decision making", Procedia - Social and Behavioral Sciences, Amsterdam, vol.156, pp.24-29, 2014. DOI: https://doi.org/10.1016/j.sbspro.2014.11.113

[3]M. Ahmad, S.Z. Ali Shah and Y. Abbass, "The role of heuristic-driven biases in entrepreneurial strategic decision-making: Evidence from an emerging economy", Management Decision, Bradford, vol. 59, pp. 669-691, 2021. DOI: https://doi.org/10.1108/md-09-2019-1231

[4]J.M. Haynie, D.A. Shepherd, and H. Patzelt, "Cognitive adaptability and an entrepreneurial task: the role of metacognitive ability and feedback",

Entrepreneurship Theory and Practice, Hoboken, NJ,
No.36, pp.237-265, 2012. DOI: https://doi.org/10.1111/j.1540-6520.2010.00410.x

[5]R.D. Ireland, M.A. Hitt and D.G. Sirmon, “A model of strategic entrepreneurship: the construct and its dimensions", Journal of Management, Amsterdam, vol.29, pp.963-989, 2003. DOI: https://doi.org/10.1016/s0149-2063(03)00086-2

[6] J.M. Haynie and D.A. Shepherd, "A measure of adaptive cognition for entrepreneurship research", Entrepreneurship Theory and Practice, Hoboken, NJ, vol.33, pp.695-714, 2009. DOI:

https://doi.org/10.1111/j.1540-6520.2009.00322.x

[7]G.G. Dess and D. Beard, "Dimensions of organizational task environments", Administrative Science Quarterly, Ithaca, NY, vol.29, pp.5273,1984. DOI: https://doi.org/10.2307/2393080

[8] M.A. Korsgaard, D.M. Schweiger and H.J. Sapienze (1995), "Building commitment, attachment, and trust in strategic decision making: the role of procedural justice", Academy of Management Journal, New York, vol.38, pp.60-84. DOI: https://doi.org/10.2307/256728

[9]J.V. Wright, "Reflections on reflection", Learning \& Instruction, Amsterdam, vol.26, pp.59-68, 1992. DOI: https://doi.org/10.1016/0959-4752(92)90005-7

[10]M. Botha and A. Bignotti, "Exploring moderators in the relationship between cognitive adaptability and entrepreneurial intention: findings from South Africa", International Entrepreneurship \& Management Journal, Berlin, vol.13, pp.10691095, 2017. DOI: https://doi.org/10.1007/s11365017-0437-8

[11]A. Efklides, "Metacognition and affect: what can metacognitive experiences tell us about the learning process?", Educational Research Review, Amsterdam, vol.1, pp.3-14, 2006. DOI: https://doi.org/10.1016/j.edurev.2005.11.001

[12]C. Cahir and K. Thomas, "Asymmetric effects of positive and negative affect on decision making", Psychological Reports, Thousand Oaks, vol.106, pp.193-204, 2010. DOI: https://doi.org/10.2466/PR0.106.1.193-204

[13]M.A. Carpenter and J.W. Fredrickson, “Top management teams, global strategic posture and the moderating role of uncertainty", Academy of Management Journal, New York, vol. 44, pp.533545, 2001. DOI: https://doi.org/10.2307/3069368 
[14]C.L. Zhang and H. Wang, "CEO learning goal orientation and firm innovation: the mechanism and boundary conditions", Journal of Small Business

Management, Hoboken, NJ, vol.58, pp.948-974, 2020.

DOI: https://doi.org/10.1111/jsbm.12537

[15]A.L. Wenden, "An introduction to metacognitive knowledge and beliefs in language learning: beyond the basics", System, Amsterdam, No,27, pp.435-441, 1999. DOI: https://doi.org/10.1016/S0346-251X(99)00043-3

[16]Q. Miao, "The impacts of regulatory focus on entrepreneurial decision making", Chinese Journal of Applied Psychology, Hangzhou, vol.12, pp.232-238, 2006. DOI:https://doi.org/10.1109/ICMSS.2009.5303901
[17] D. Miller and P.H. Frieson, "Innovation in conservative and entrepreneurial firms: two models of strategic momentum", Strategic Management Journal, Hoboken, NJ, vol. 3, pp.1-25, 1982. DOI: https://doi.org/10.1002/smj.4250030102

[18]A.F. Hayes , "Introduction to mediation, moderation, and conditional process analysis: a regression-based approach", Guilford Press, New York, vol.51, pp.335-337, 2014. DOI: https://doi.org/10.1111/jedm.12050 